\title{
Application of a device used for observation of controlled thermal processes in a furnace
}

\author{
Examples of delubrication, oxidation, melting, pyrolysis, and combustion
}

\author{
Marek Hebda $\cdot$ Mateusz Laska • \\ Magdalena Szechyńska-Hebda
}

Received: 1 December 2012/Accepted: 22 March 2013/Published online: 17 April 2013

(C) The Author(s) 2013. This article is published with open access at Springerlink.com

\begin{abstract}
This paper describes an appliance that allows to visually observe phenomena occurring in the studied materials during heating, from room temperature to $600{ }^{\circ} \mathrm{C}$. The design criteria and device construction are described in details. The device allows for visual observation of physical phenomena of various material types, e.g., organic matter, polymers, and even observation of sintering mechanisms. Analysis of lubricant evaporation from powder metals (an aluminum alloy) in different atmospheres is shown. The featured device can also be used for interpretation of material defects. This is presented on the example of heating the aluminum alloy in an atmosphere containing oxygen (to simulate a furnace leakage). In addition, the influence of experimental atmosphere on melting and sintering processes is demonstrated. Another application of the presented device can be the visual observation of differences between combustion and pyrolysis processes. Our results show that the presented device is complementary with an advanced thermoanalysis apparatus which, in turn, does not allow visual observation of samples.
\end{abstract}

M. Hebda ( ()$\cdot$ M. Laska

Institute of Material Engineering, Cracow University of

Technology, ul. Warszawska 24, 31-155 Krakow, Poland

e-mail: mhebda@pk.edu.pl

M. Szechyńska-Hebda

Institute of Plant Physiology, Polish Academy of Sciences,

Niezapominajek 21, 30-239 Krakow, Poland

M. Szechyńska-Hebda

Department of Plant Genetics, Breeding and Biotechnology,

Warsaw University of Life Sciences, ul. Nowoursynowska 159,

02-776 Warszawa, Poland
Keywords Pyrolysis - Combustion · Sintering - Furnace · Protective atmospheres . Thermal effects

\section{Introduction}

Various physical and chemical phenomena occur in materials subjected to changing temperatures e.g., as simple as melting and crystallization and more complex ones, such as sintering, phase transition, combustion, self-ignition, and change of optical properties. Modern research apparatuses allow for precise determination of the temperatures of these phenomena, for defining their kinetics, mass, and dimensional changes. In most cases it is impossible to directly or simultaneously observe the visual changes taking place in the studied materials. Currently, in modern test equipment it is common to include the so-called coupled methods (allowing to perform several independent measurements at the same time, e.g., the measurement cycle in differential scanning calorimetry/thermogravimetry/quadrupole mass spectrometry; DSC/TG/QMS), which facilitate interpretation of the registered thermal effects, mass changes or released gas products [1-9]. From the results it can be concluded which phenomena are being dealt with, but observation of the sample can be conducted only before and/or after the experiment. The device presented in this article allows to extend knowledge on the studied material/ phenomenon through continuous observation during heating from room temperature to $600{ }^{\circ} \mathrm{C}$ in a controlled gas atmosphere. The device allows to apply identical parameters (temperature, atmosphere, heating rate) as in, e.g., commercially available furnaces or laboratory apparatuses, and therefore gives the possibility to compare the received results. The significance of this aspect can be seen when taking into consideration some worldwide companies that 
produce thermal analysis equipment and try to improve them with units allowing direct observation. An example of such equipments is recently developed the MP90 apparatus (Mettler-Toledo). However, the application of MP90 apparatus is limited and the determination of the melting point of substances (mostly plastic) planted inside a capillary tube can be performed in a temperature range that does not exceed $400{ }^{\circ} \mathrm{C}$. Moreover, there is not possibility to choose atmosphere during sample examinations. Another solution was presented as a heating table Linkam LTS420 (OPTA-TECH). The proposed system allows the laboratory for conducting the tests at temperatures ranging from -196 to $+1,500{ }^{\circ} \mathrm{C}$ and observe heating-cooling samples under polarizing microscope. However, again, the most important limitation are studies only under natural air atmosphere.

\section{Experimental}

The studies were performed on a self-made apparatus. Its technical features and possible applications are presented below. The unit construction allows for research on samples of any shape. Restrictions only result from the dimensions of the unit itself. Figure 1 shows a diagram of the workstation with an electric circuit, while Fig. 2 presents a $3 \mathrm{D}$ visualization of the unit's frame. The maximum sample length cannot exceed $97 \mathrm{~mm}$ for this technical appliance. However, the unit's dimensions can be freely modified. The proposed dimensions allow for studies on a majority of standardized samples used in material testing. The unit was built using stainless steel (X5CrNi18-10) to protect it from corrosion and reactions occurring between the sample, gas and apparatus. The object can be observed through a window made of flameproof ceramic glass (Węgier Glass) which maintains its properties up to a temperature $800{ }^{\circ} \mathrm{C}$. Fiber-Plast (Notec System) glass fiber was used for insulation due to its low heat-transfer coefficient $\left(0.11 \mathrm{~W} \mathrm{mK}^{-1}\right.$ at $400{ }^{\circ} \mathrm{C}$ ), low shrinkage (up to $2 \%$ after baking), high temperature difference resistance, and good formability. Observation of phenomena occurring during thermal process can be performed with the naked eye or with an additional equipment, e.g., a magnifying glass, stereoscopic microscope or camera, all of which allow not only observation under magnification, but also video capture, and computer analysis afterward. Besides the above-described components of our device there are also a $1,500 \mathrm{~W}$ pipe heater $(70 \mathrm{~mm}$ in diameter and $150 \mathrm{~mm}$ in height), a type $\mathrm{K}$ thermocouple and a temperature regulator (Shinko ACS-13A) controlling e.g., the heating rate and transferring data to a computer. The device has been constructed in such a way that each type of atmosphere can be used. Furthermore, the atmosphere can be of a controlled flow rate (at a rate controlled by an external device such as a reducer or rotameter) or it can remain static. In addition, the chamber can be evacuated first before filling with a protective gas. To insure safety a gas removal system (e.g., a fume hood) must be used.

In order to check accuracy of temperature obtained in the constructed device and it's relation to the observed physical effects comparative studies were performed with STA 409 CD (Netzsch) with advanced coupling techniques (DSC/TG) and gas analysis by Quadruple Mass Spectrometry (QMS 403/5 SKIMMER). Identical parameters were used for measurements with both units, i.e., a heating rate of $10{ }^{\circ} \mathrm{C} \mathrm{min}^{-1}$, a protective atmosphere of argon of 5.0 purity $(99.999 \%)$ or air, and a flow rate of $80 \mathrm{~mL} \mathrm{~min}^{-1}$. DSC control measurements were performed for $10 \mathrm{mg}$ of the samples in closed aluminum crucibles that were $40 \mathrm{~mL}$ in volume with a $50 \mu \mathrm{m}$ hole in the lid. An empty, closed aluminum crucible was used as a reference. The apparatus was calibrated using indium, tin, bismuth, zinc, and aluminum as the reference material. The heat flow signal was calibrated by the melting heat of the abovementioned elements. Quadruple Mass Spectrometry (QMS) with an electron ionization source was operated in MID (Multiple Ion Detection) mode. The QMS was checked using Calcium Oxalate Monohydrate (Fluka). The DSC/ TG/QMS data were analyzed using Proteus software (ver. 5.2.0) from Netzsch. All of the presented curves were corrected against empty runs.

\section{Results and discussion}

\section{Observation of lubricant evaporation}

from metal powders

Lubricants are commonly added to metal powders during technological production. The volume fraction of lubricants is maintained between 1 and $2 \%$, but the chemical composition is never published [2, 10-14]. Lubricants are added mainly to reduce friction forces during formation of the product, thus to obtain highly densified details and homogeneous density distribution $[15,16]$. Lubricants need to be fully removed before sintering because they can have a negative impact on the part's surface and appearance, and they can dramatically lower the part's mechanical properties [14]. In general, this is performed during the heating stage of sintering compacts under an oxidizing or neutral atmosphere.

An aluminum powder called Alumix 431D was used for the analysis of lubricant removal in different atmospheres (argon was used for pyrolysis, air was used for combustion). The powder's chemical composition is presented in Table 1 . The powder was uniaxially pressed at $600 \mathrm{MPa}$ 
Fig. 1 Chart of the device with an electric circuit 1 temperature controller, 2 solid-state relay, 3 thermocouple, 4 body of the device, 5 camera

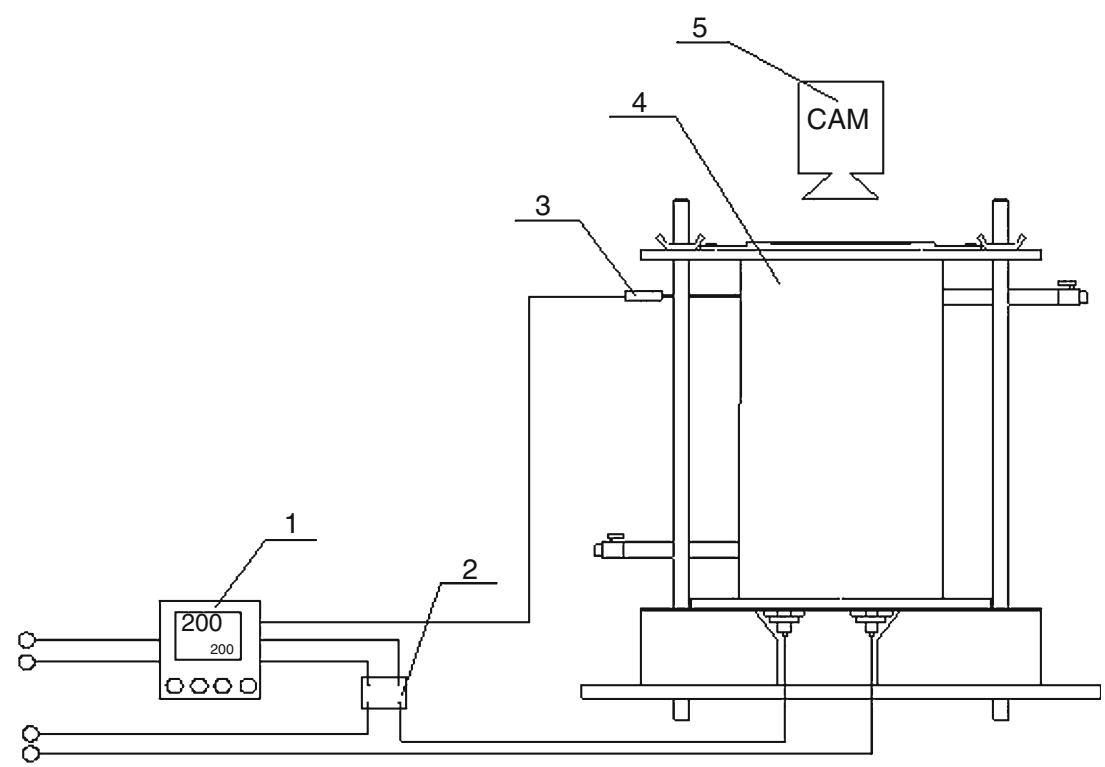

Fig. 2 3D visualization of the body of the device: 1 pressure bolts, 2 observing glass,

3 pressure ring, 4 top plate, 5 threaded rods, 6 channel inlet gas, 7 housing, 8 insulating pad, 9 base plate, 10 support, 11 heater

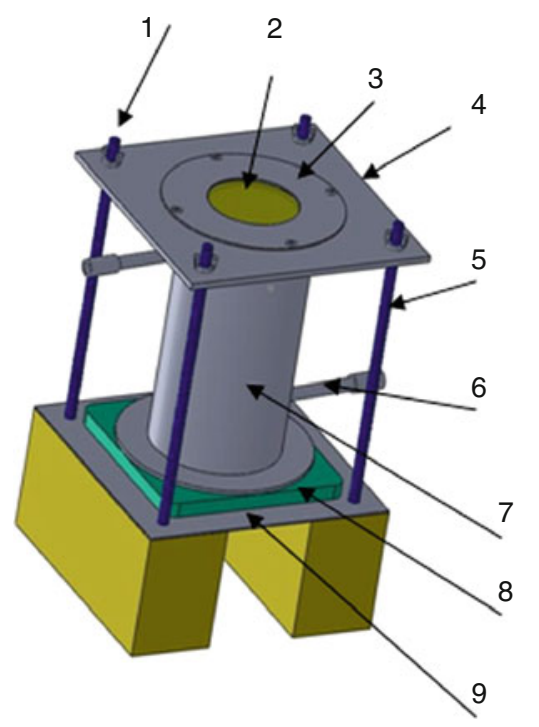

into rectangular samples $12 \times 30 \times 5 \mathrm{~mm}$ in size and then were heated to $600{ }^{\circ} \mathrm{C}$.

Figure 3 shows the most characteristic effects observed during the heating. The lubricant removal process began at about $200{ }^{\circ} \mathrm{C}$ under argon atmosphere (Fig. 3a-e) since liquid phase was observed on the sample surface. In a temperature range of $300-350{ }^{\circ} \mathrm{C}$ the highest rate of delubrication occurred and a very intensive evaporation was observed. At temperature higher than $400{ }^{\circ} \mathrm{C}$ no effects

Table 1 Chemical composition of the studied alloyed aluminum powder Alumix 431D

\begin{tabular}{lllll}
\hline $\begin{array}{l}\mathrm{Cu} / \\
\text { mass\% }\end{array}$ & $\begin{array}{l}\mathrm{Mg} / \\
\text { mass\% }\end{array}$ & $\begin{array}{l}\mathrm{Zn} / \\
\text { mass\% }\end{array}$ & $\begin{array}{l}\text { Lubricant/ } \\
\text { mass\% }\end{array}$ & $\begin{array}{l}\mathrm{Al} / \\
\text { mass\% }\end{array}$ \\
\hline 1.5 & 2.5 & 5.5 & 1.2 & 89.3 \\
\hline
\end{tabular}

were detected and the surface of the sample was metallic/ silvery. It can thus be stated that application a protective atmosphere of neutral gas (argon) fully protects the sample surface from oxidation.

A different pattern of changes was observed during delubrication in air atmosphere (Fig. $3 \mathrm{f}-\mathrm{j}$ ). At a temperature of $117^{\circ} \mathrm{C}$, which is about $100{ }^{\circ} \mathrm{C}$ lower than in the argon atmosphere, the lubricant started to be removed. This was observed as very small silvery/metallic areas on the surface of the sample. At $150{ }^{\circ} \mathrm{C}$ yellow discolorations were observed on the sample surface, thus indicating areas where organic matter coming from the lubricant had started to combust. With a temperature rise the liquid areas grew due to coupling, and their color changed into a darker one. In a temperature range of $250-340{ }^{\circ} \mathrm{C}$ evaporation of the gas products could be seen, although the intensity was lower in 
Fig. 3 Influence of the atmosphere on delubrication (pyrolysis $3 \mathbf{a}-\mathbf{e}$ and combustion $3 \mathbf{f}-\mathbf{j}$ ) and on the surface quality of the Alumix 431D alloy after sintering

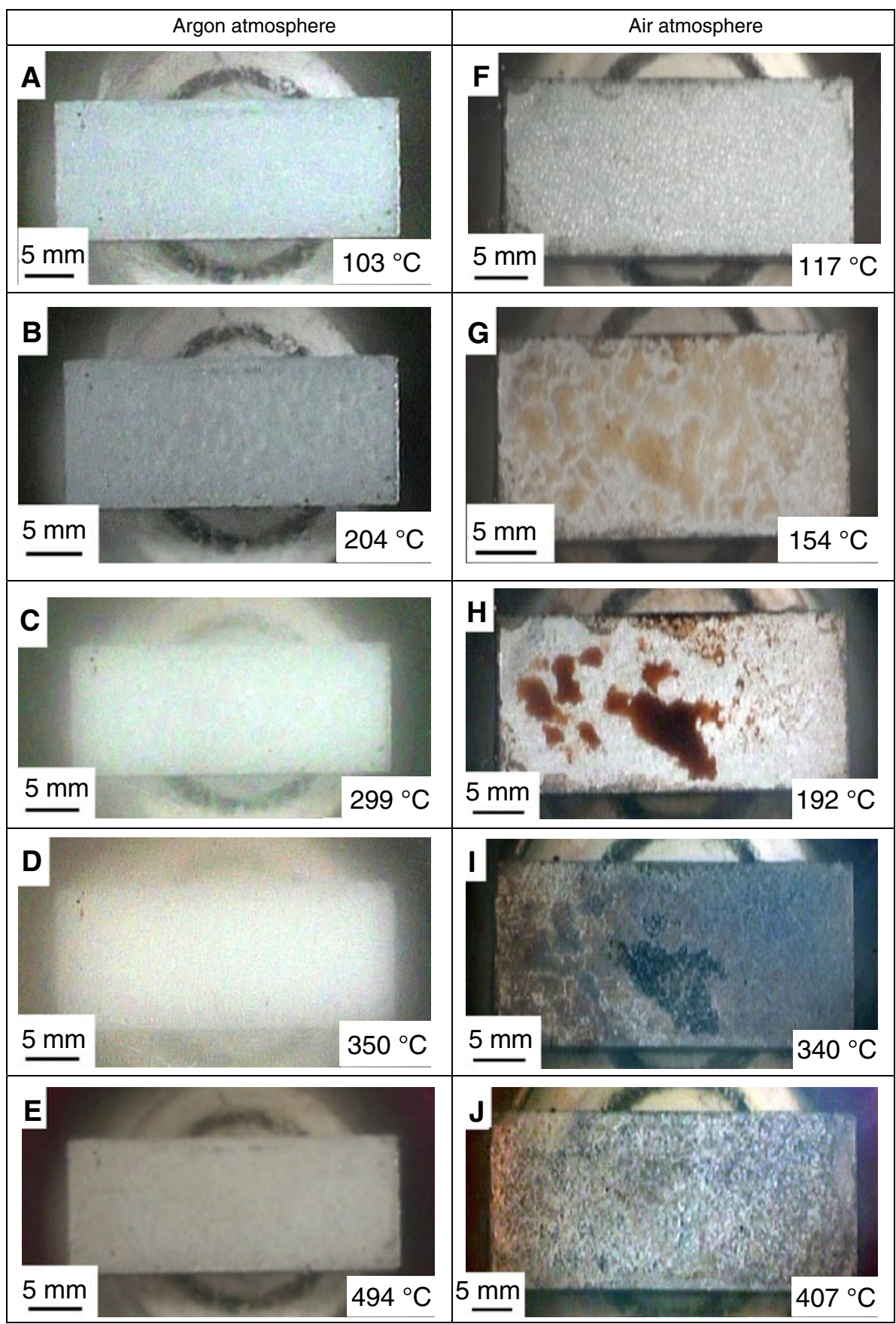

comparison to those sintered under the argon atmosphere. Above a temperature of $400{ }^{\circ} \mathrm{C}$ no sample changes were observed, although on the sample's surface many small black discolorations as the effect of material oxidation, were determined.

Figure 4 shows the TG results recorded during heating of Alumix 431D powder in argon and air atmosphere. The identical parameters were used as in processes in constructed device (presented on Fig. 3). The powder before analysis was uniaxially pressed at $600 \mathrm{MPa}$ into rectangular samples $4 \times 4 \times 15 \mathrm{~mm}$ in size due to the measuring unit's limitations.

There were three intervals of mass change on the TG curve in air atmosphere. The first slow mass loss up to $320{ }^{\circ} \mathrm{C}$ was related to the delubrication process, the second rapid one in temperature range from 320 to $460{ }^{\circ} \mathrm{C}$ can be explained by the removal of hydrocarbons/carbon from the sample surface and the third stage, above $460{ }^{\circ} \mathrm{C}$ associated with mass increase can be the result of the oxidation process. In contrast, the removal of lubricant takes place as 


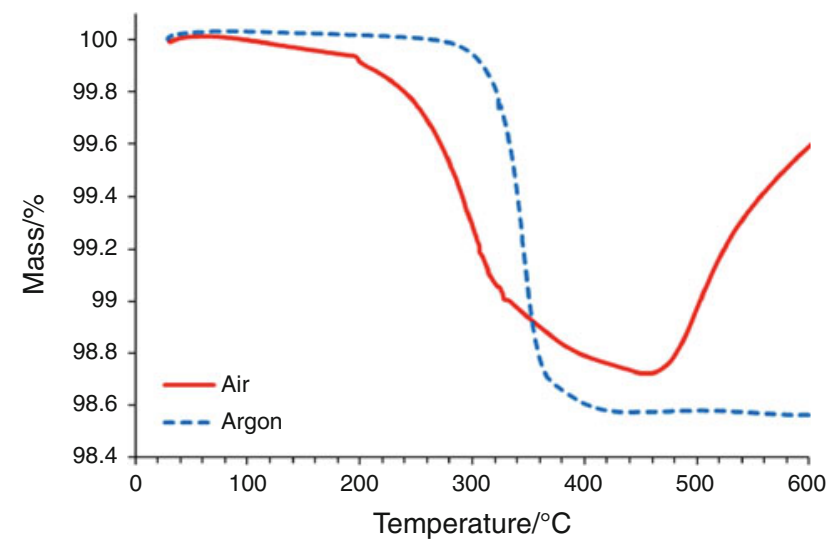

Fig. 4 TG curves for the Alumix 431D powder heated in argon and air atmosphere

a single step in the temperature range from 300 to $450{ }^{\circ} \mathrm{C}$ in inert atmosphere. The dominating mechanism of delubrication is associated with decomposition and degradation of the large organic molecules not only into lower mass products such as simple $\mathrm{H}_{2} \mathrm{O}$ or $\mathrm{CO}_{2}$ compounds, but also into short chain hydrocarbons.

The obtained results are complimentary with those achieved on the constructed device. Temperature accuracy of the corresponding delubrication effects was confirmed. TG characteristic also confirmed observations of material oxidation in air atmosphere (seen as a TG rises above $460{ }^{\circ} \mathrm{C}$ ) and preservation of the material's surface in argon atmosphere. Additional information that was registered during the TG studies was a precise mass change value allowing to determine the temperature in which all the lubricants evaporated.

Observation of material defects formed

during the heating process

Optimized production parameters must be strictly followed in every technological process. A change or failure to follow them usually results in an abnormality of the constructed product. In powder metallurgy two of the most important technological parameters are adequate atmosphere and sintering temperature [17-21].

An observation of atmosphere influence on product abnormalities was performed. The changes in protective gas (argon) purity or the device tightness were simulated by a small addition of air (a gas flow of $4 \mathrm{~mL} \mathrm{~min}^{-1}$ ) during the heating process. The research was performed for Alumix 431D powder heated to $600{ }^{\circ} \mathrm{C}$. Figure 5 shows the anomalies that appeared on the sample's surface in the form of spherical bubbles, which were created during the heating period. The blistering on the sample surface was observed when the material was heated above a temperature of $460{ }^{\circ} \mathrm{C}$. This effect was the result of oxidation of the sample surface.
Direct observation of the samples in the constructed device allowed to explain the source of the abnormalities that were taking place on the material (its partial oxidation) and to precisely determine the temperature at which those failures occurred. Studies performed on different advanced techniques (i.e., thermoanalysis) probably would not allow to unequivocally determine the character and manner of how the flaw had occurred. The formation of bubbles on the surface of the samples would not give any mass changes on the TG and/or energetic effects on DSC curves. Therefore, direct observation of the studied samples allows for proper interpretation of the phenomena taking place.

Observation of the influence of applied atmosphere on the tin melting process

The atmosphere in which the technological processes are performed is often a key factor in obtaining high quality details. The correct selection of atmosphere prevents the material from oxidizing and allows for changes in surface properties, i.e., using carbonization atmospheres. In powder metallurgy, reducing atmospheres are the most common because of their ability to reduce the oxide layers covering the powder particles. This phenomenon provides conditions for effective diffusion process between powder particles [22]. A comparison of the results shown in Fig. $6 \mathrm{a}-\mathrm{h}$ allows to determine the atmosphere's (air or argon) influence on the material's melting process of tin particles (Poch, purity $99.5 \%$ ).

The results showed that along with temperature rise the stable oxides developed on the particles surface in air atmosphere. Although, melting temperature of tin is $232{ }^{\circ} \mathrm{C}$ the developed oxides created some kind of "layer" that prevented the melting of tin particles and merging together, even during overheating above the melting temperature (Fig. 6b-d). It was observed that the particles which surfaced were flat at the beginning of heating process (Fig. 6a) became spherical at $271{ }^{\circ} \mathrm{C}$ (Fig. 6d) as a result of both the liquid phase and surface tension changes.

Application of argon atmosphere for tin sintering was more suitable. The particles, despite their original surface

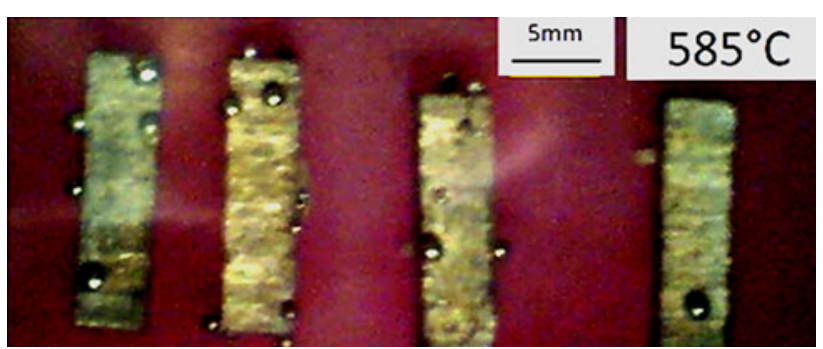

Fig. 5 Spherical bubbles on the sample surface as an effect of partial material oxidation during the heating process 
Fig. 6 Tin melting process in air and argon

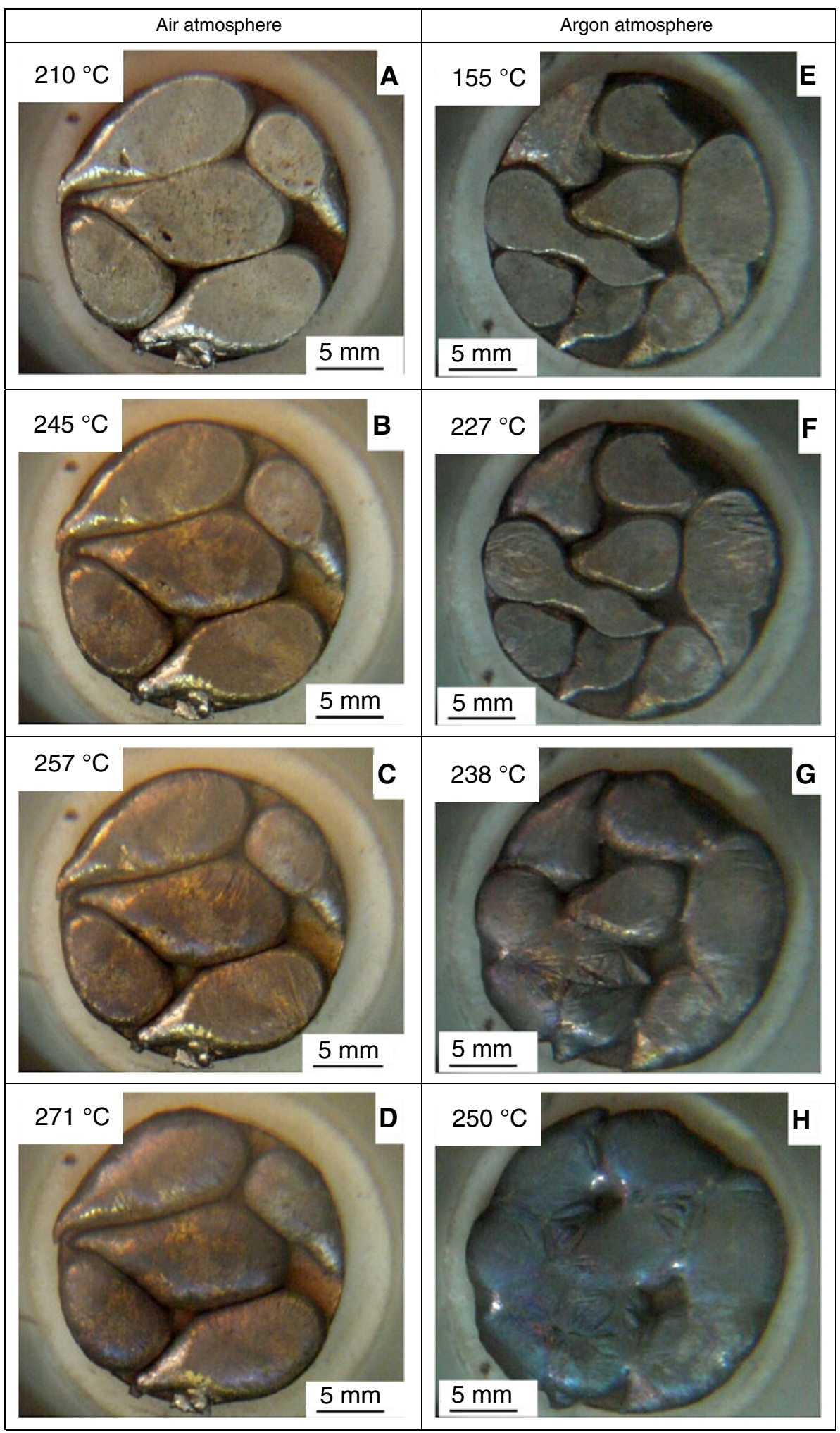

oxidation, changed their shape at $227^{\circ} \mathrm{C}$ (spheroidization, Fig. 6f) and at $238{ }^{\circ} \mathrm{C}$ (Fig. 6g) the local merging point started taking place. A further temperature rise resulted in growth of the existing connections and the creation of new necks in studied material. In general, this effect can be compared to processes of necks formation and area growth particles occurring during metal powder sintering. Diffusion process resulting in particles connections allows to obtain desirable mechanical properties [22]. On the other hand, in a sintered material structure empty spaces can be 
seen between the particles (porosity), which is analogical to the macro scale visible holes in Fig. 6h. Conclusions from these observations can be generalized into whole sintering and thermochemical treatment processes in which the atmosphere plays the main role.

\section{Comparison of pyrolysis and combustion processes}

In this experiment we examined flame retardancy, smoke emission, and dimensional and color changes taking place during thermal degradation of poplar wood samples from two different trees (Populus tremula $\times$ tremuloides) in argon and air atmosphere. The process in air atmosphere was related to combustion, whereas pyrolysis occurred in argon. Observations were performed for samples heated to $500{ }^{\circ} \mathrm{C}$. All of the samples were laid on a horizontal concave sample holder to prevent the sample from moving during heating. The changes were registered with a camera and are shown in Fig. 7.

When the process was performed in argon, the sample color change began at $245{ }^{\circ} \mathrm{C}$ and became darker with a temperature rise (Fig. $7 \mathrm{a}-\mathrm{e}$ ). At about $245^{\circ} \mathrm{C}$ rapid volume and dimensional changes started taking place (Fig. $7 \mathrm{~b}$ ). This process advanced with a temperature rise up to $400{ }^{\circ} \mathrm{C}$ (Fig. 7e). In wood-based samples, smoke production is usually the most important concern, and research is usually directed toward smoke suppression. At $338{ }^{\circ} \mathrm{C}$ the process of pyrolysis was accompanied by smoke emission (Fig. 7d). This effect showed evolution with time and probably indicates the formation of less vapor-phase aromatics, which are poorly combustible and potent smoke formers. Smoke emission was less visible under air atmosphere (Fig. $7 \mathrm{f}-\mathrm{j}$ ). In general, the combustion process of wood samples can be divided into three steps: (1) a non-flaming mode at $30-250{ }^{\circ} \mathrm{C}$ which showed a similar effect of wood darkness to the pyrolysis process (Fig. 7f), (2) a flaming mode at $250-350{ }^{\circ} \mathrm{C}$ followed by dimensional changes in the sample (shrinking) (Fig. $7 \mathrm{~g}-\mathrm{i}$ ), and (3) an after-glowing mode starting at $350{ }^{\circ} \mathrm{C}$ with "whitening" of samples that was related to ash formation (Fig. $7 \mathrm{i}-\mathrm{j}$ ). Smoke emission occurs during the flaming step at $250-279{ }^{\circ} \mathrm{C}$, while there is no smoke evolved in both the non-flaming step and the afterglowing step. This result showed that the visualization of thermal processes of wood can be significant in understanding smoke emission, sample auto-ignition, and sample dimensional changes and this physical effects can be correlated to the adequate temperatures.

The pyrolysis and combustion processes were also compared based on results from the TG/DSC/QMS analysis. As is shown in Fig. 8, the TG and DSC curves of wood recorded in this study are similar to curves obtained by other authors (e.g., [23, 24]). The thermal degradation of wood expressed as a TG curves can be divided into three stages (Fig. 8). The initial low temperature mass loss at $100{ }^{\circ} \mathrm{C}$ corresponds to loss of moisture and is a common feature observed for lignocellulose fibers [25, 26]. No degradation took place and the wood was considered as thermally stable at this stage. This was also confirmed by the lack of color changes during an observation performed in the furnace (Fig. 7). In the second stage, rapid mass loss occurred in the temperature range $300-375^{\circ} \mathrm{C}$. The mass loss was about 85 and $70 \%$ for pyrolysis in argon atmosphere and combustion in air, respectively. The second stage corresponds to the main decomposition processes and it can be attributed to the thermal decomposition of hemicellulose and cellulose [27-31]. Pyrolysis and combustion decomposition processes in the temperature range $300-375^{\circ} \mathrm{C}$ can also be linked to smoke occurrence and sample darkening in argon atmosphere as well as to a flaming mode following by dimensional changes of the samples in air. After the second stage, mass losses of the wood's residual materials were slower for the argon atmosphere while they progressed gradually for air. This effect was mimicked on the DSC and MID curves. DSC clearly showed two combustion steps in the wood samples on the basis of the temperature scale. The first exothermic peak in the DSC curve at $345^{\circ} \mathrm{C}$ represented the main mass loss on the TG curves $(70 \%)$, whereas the second DSC peak, starting at $350{ }^{\circ} \mathrm{C}$ (the temperature of TG bending) and with maximum at about $370{ }^{\circ} \mathrm{C}$, was lower but wider than in the first step and was related to a mass loss of about $20 \%$ on the TG curve. The first DSC peak could be attributed to the decomposition of hemicellulose [25], although the values obtained in this study were slightly higher than the usual range attributed to hemicellulose thermal decomposition, from 270 to $281^{\circ} \mathrm{C}$ [31]. The second peak is usually regarded as cellulose degradation step [5]. Hemicelluloses present lower thermal stability than cellulose due to the fact that they are amorphous, whereas cellulose is crystalline [32]. Furthermore, the presence of acetyl groups in hemicellulose lowers their stability [33]. In contrast, degradation process in argon showed one endothermic peak, much narrow than the two-step decomposition process in air. On the other hand, similar one-step characteristic of gaseous products were observed during the decomposition of both, pyrolysis and combustion processes (Fig. 9). Although, the peaks representing gaseous volatiles for all of the presented $\mathrm{m} / \mathrm{z}$ were much wider, with a long tail on the high temperature side when recorded in air atmosphere and it can be correlated with specific TG and DSC effects, these results also indicate that individual thermal effects (e.g., two peaks) recorded during DSC analysis, are not necessarily mimicked by gaseous products. It can be result of similar gaseous products from cellulose and hemicelluloses and overlapping the decomposition processes of both polymers. 
Fig. 7 Pyrolysis (7a-e) and combustion $(7 \mathbf{f}-7 \mathbf{j})$ processes of two poplar wood samples at chosen temperatures

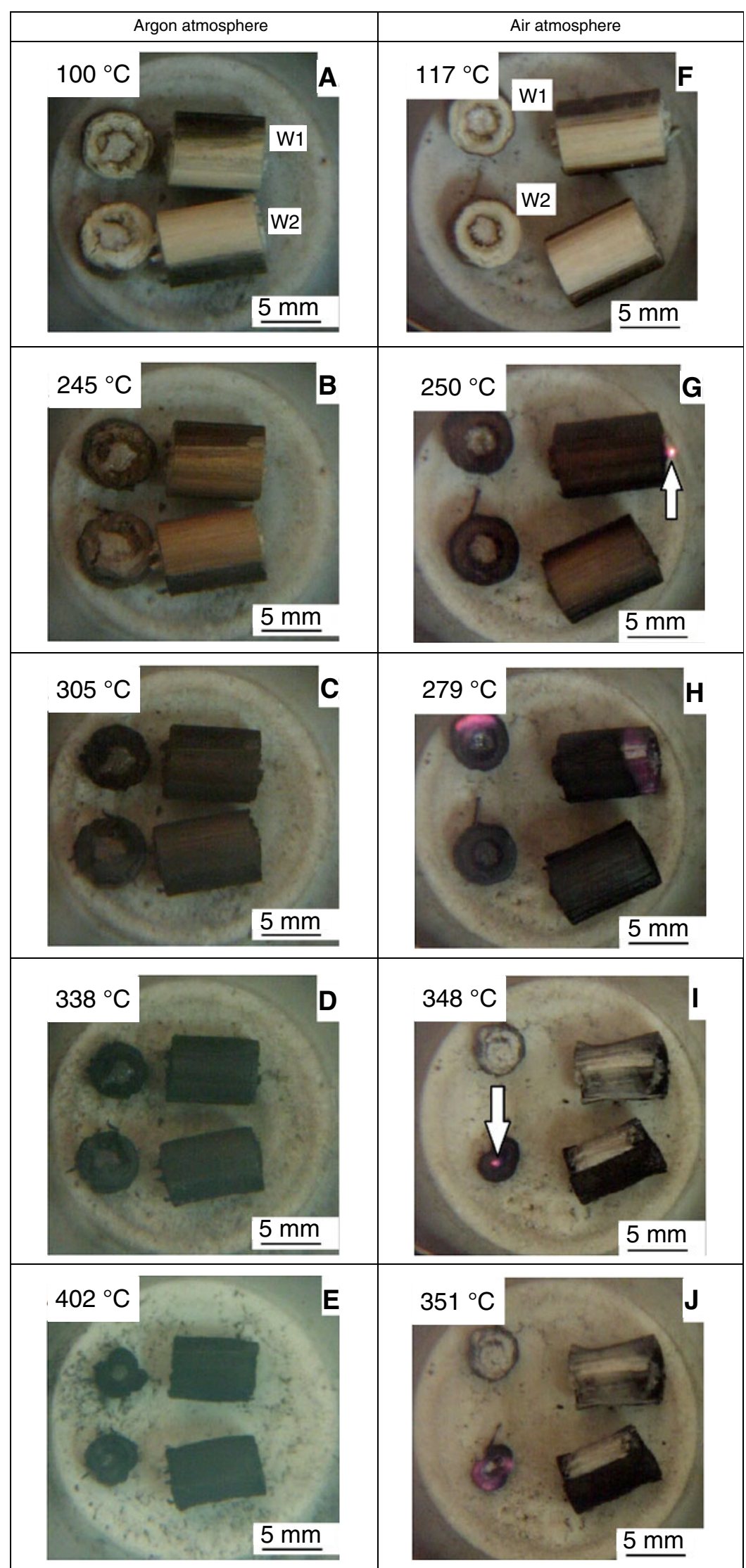


Fig. 8 TG and DSC curves for wood samples studied in argon and air atmosphere

Fig. 9 Mass spectrum obtained via MID mode recorded for wood samples heated to $500{ }^{\circ} \mathrm{C}$ in argon and air atmosphere
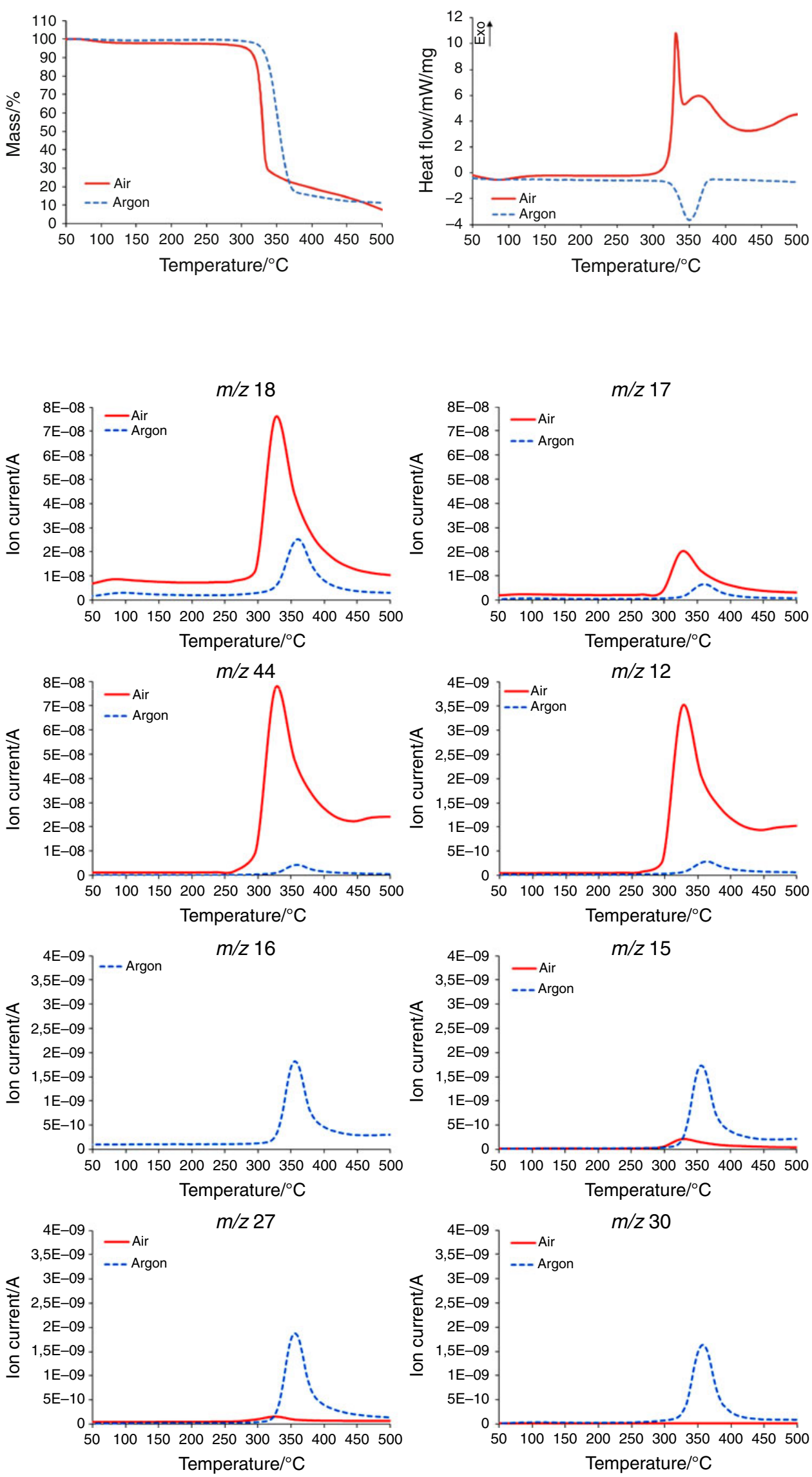
It is known that the thermal degradation of lignocellulosic material usually takes place via two competing pathways: dehydration and depolymerization. The first way leads directly to char and gaseous products, which result from cleavage of the $\mathrm{C}-\mathrm{O}$ bonds (mainly $\mathrm{CO}, \mathrm{CO}_{2}$ and $\mathrm{H}_{2} \mathrm{O}$ ), and the second way leads to tar and organic volatiles [34]. The MID records (Fig. 9) indicated that the occurrence of both pathways depends on the atmosphere that was applied. Starting from about $300-400{ }^{\circ} \mathrm{C}$, the highest intensities were detected for water $(\mathrm{m} / \mathrm{z}, 18, \mathrm{~m} / \mathrm{z}, 17)$ and carbon dioxide $(\mathrm{m} / \mathrm{z}, 44)$ in air atmosphere. An $\mathrm{m} / \mathrm{z}, 12$ mainly relating to carbon, carbon monoxide, and carbon dioxide (NIST mass spectra library) was also detected. Therefore, dehydration seems to be a more common degradation pathway in air. In contrast, ions $\mathrm{m} / \mathrm{z}$ indicating organic components: $\mathrm{CH}_{4}(\mathrm{~m} / \mathrm{z}, 16$ and $15 ; \mathrm{m} / \mathrm{z}, 16$ from study in air is not shown, since $\mathrm{m} / \mathrm{z} 16$ is related to oxygen present in air atmosphere), $\mathrm{C}_{2} \mathrm{H}_{6}(\mathrm{~m} / \mathrm{z} 27$ and $30 ; \mathrm{m} / \mathrm{z} 28$ is not shown since it cannot be compared to analysis in air atmosphere) from the depolymerization process [7] were identified at a higher level in argon atmosphere. It can be concluded that depolymerization is a more common process when oxygen is less abundant in the atmosphere.

\section{Conclusions}

The presented device allows to observe many different physical and chemical processes that take place in materials during heating to high temperatures (at least $600{ }^{\circ} \mathrm{C}$ ).

Our device can be used, e.g., to: (1) observe the changes in substances evaporation and decomposition. Our results showed that lubricant evaporation from metal powders was dependent on applied atmosphere; (2) determine the material impurities and defects under the changing temperature and atmosphere, and simulate the changes of atmosphere during studies. The small patches of oxidized surface of Alumix 431D powder was revealed as a spherical bubbles during heating process in argon atmosphere with small addition of air; (3) examine the melting points and sintering mechanisms of low temperature materials. The difference in neck formation between tin particles was shown in air and argon atmosphere; (4) study the influence of applied atmosphere on the material being analyzed. The differences between pyrolysis and combustion, flame retardancy, smoke emission, dimensional and color changes were clearly shown.

The results fully correlated with data recorded during thermoanalysis (DSC/TG/QMS). Therefore, presented device can be used as a simple technique that is complementary to more sophisticated method.

Direct observation of physical and chemical phenomena allows for a clear interpretation of the obtained results.
Based on the photographic documentation it is also possible to apply the digital image processing techniques e.g., to follow sample dimensional changes in time. Moreover, the device allows for an analysis of samples with dimensions of up to $10 \mathrm{~cm}$ in contrast to most of the more advanced methods where the samples are very small.

Acknowledgments The study was supported by the Programme Innovative Economy grant POIG.01.01.02-00-015/09-00 and the National Centre for Research and Development grant PBS1/A8/16/ 2013 (ID 180606).

Open Access This article is distributed under the terms of the Creative Commons Attribution License which permits any use, distribution, and reproduction in any medium, provided the original author(s) and the source are credited.

\section{References}

1. Rouff AA. The use of TG/DSC-FT-IR to assess the effect of $\mathrm{Cr}$ sorption on struvite stability and composition. J Therm Anal Calorim. 2012;110:1217-23.

2. Hebda M, Gądek Sz, Kazior J. Thermal characteristics and analysis of pyrolysis effects during the mechanical alloying process of Astaloy CrM powders. J Therm Anal Calorim. 2012;108(2):453-60.

3. Washbourne CL, Renforth P, Manning DAC. Investigating carbonate formation in urban soils as a method for capture and storage of atmospheric carbon. Sci Total Environ. 2012;431:166-75.

4. Mathan ND, Arunjunairaj M, Rajkumar T, Ponraju D, Vijayakumar ChT. Thermal degradation of pentaerythritol phosphate alcohol, TG and TG-MS studies. J Therm Anal Calorim. 2012; 110:1133-41.

5. Szechyńska-Hebda M, Hebda M, Mierzwiński D, Kuczyńska P, Mireka M, Wędzony M, van Lammerene A, Karpiński S. Effect of cold-induced changes in physical and chemical leaf properties on the resistance of winter triticale ( 3 Triticosecale) to the fungal pathogen Microdochium nivale. Plant Pathol. 2012. doi:10.1111/ ppa.12001.

6. Lopez-Capel E, Abbott GD, Thomas KM, Manning DAC. Coupling of thermal analysis with quadrupole mass spectrometry and isotope ratio mass spectrometry for simultaneous determination of evolved gases and their carbon isotopic composition. J Anal Appl Pyrol. 2006;75:82-9.

7. Streibel T, Geißler R, Saraji-Bozorgzad M, Sklorz M, Kaisersberger E, Denner T, Zimmermann R. Evolved gas analysis (EGA) in TG and DSC with single photon ionisation mass spectrometry (SPI-MS): molecular organic signatures from pyrolysis of soft and hard wood, coal, crude oil and ABS polymer. J Therm Anal Calorim. 2009;96:795-804.

8. Saraji-Bozorgzad MR, Streibel T, Kaisersberger E, Denner T, Zimmermann R. Detection of organic products of polymer pyrolysis by thermogravimetry-supersonic jet-skimmer time-of-flight mass spectrometry (TG-Skimmer-SPI-TOFMS) using an electron beam pumped rare gas excimer VUV-light source (EBEL) for soft photo ionization. J Therm Anal Calorim. 2011;105:691-7.

9. Ishak MR, Leman Z, Salit MS, Rahman MZA, Uyup MKA, Akhtar R. IFSS, TG, FT-IR spectra of impregnated sugar palm (Arenga pinnata) fibres and mechanical properties of their composites. J Therm Anal Calorim. 2012. doi:10.1007/s10973-012-2457-5.

10. MacAskill IM, Heard DW, Bishop DP. Effects of silicon on the metallurgy and sintering response of $\mathrm{Al}-\mathrm{Ni}-\mathrm{Mg}$ PM alloys. Mater Sci Eng. 2007;452-453:688-98. 
11. Schaffer GB, Huo SH, Drennan J, Auchterlonie GJ. The effect of trace elements on the sintering of an $\mathrm{Al}-\mathrm{Zn}-\mathrm{Mg}-\mathrm{Cu}$ alloy. Acta Mater. 2001;49(14):2671-8.

12. Schaffer GB, Hall BJ, Bonner SJ, Huo SH, Sercombe TB. The effect of the atmosphere and the role of pore filling on the sintering of aluminium. Acta Mater. 2006;54(1):131-8.

13. Grayson GN, Schaffer GB, Griffiths RJ. Observations of oxide films on fatigue fracture surfaces of a sintered $2 \mathrm{xxx}$ series aluminium alloy. Mater Sci Eng. 2007;454-455:99-103.

14. Baum MM, Becker RM, Lappas AM, Moss JA, Apelian D, Saha D, Kapinus VA. Lubricant pyrolysis during sintering of powder metallurgy compacts. Metall Mater Trans B. 2004;35B:381-92.

15. Li YY, Ngai TL, Zhang DT, Long Y, Xia W. Effect of die wall lubrication on warm compaction powder metallurgy. J Mater Process Technol. 2002;129(1):354-8.

16. Simchi A. Effects of lubrication procedure on the consolidation, sintering and microstructural features of powder compacts. Mater Des. 2003;24(8):585-94.

17. Abenojar J, Velasco F, Bautista A, Campos M, Bas JA, Torralba JM. Atmosphere influence in sintering process of stainless steels matrix composites reinforced with hard particles. Compos Sci Technol. 2003;63(1):69-79.

18. Schaffer GB, Hall BJ. The influence of the atmosphere on the sintering of aluminum. Metall Mater Trans A. 2002;33(10):3279-84.

19. Bose A, German RM. Sintering atmosphere effects on tensile properties of heavy alloys. Metall Mater Trans A. 1988;19(10): 2467-76.

20. Hebda M, Gaqdek S, Kazior J. Influence of the mechanical alloying process on the sintering behaviour of Astaloy CrM powder mixture with silicon carbide addition. Arch Metall Mater. 2012;57(3):733-43.

21. Pieczonka T, Kazior J, Szewczyk-Nykiel A, Hebda M, Nykiel M. Effect of atmosphere on sintering of Alumix 431D powder. Powder Metall. 2012;55(5):354-60.

22. German RM. Powder metallurgy \& particulate materials processing. New York: Wiley; 2005.
23. Bernabe GA, Kobelnik M, Almeida S, Ribeiro CA, Crespi MS. Thermal behavior of lignin and cellulose from waste composting process. J Therm Anal Calorim. 2012;111(1):589-95.

24. Kivotidi S, Tsioptsias C, Pavlidou E, Panayiotou C. Flameretarded hydrophobic cellulose through impregnation with aqueous solutions and supercritical $\mathrm{CO}_{2}$. J Therm Anal Calorim. 2013;111(1):475-82.

25. d'Almeida ALFS, Barreto DW, Calado V, d'Almeida JRM. Thermal analysis of less common lignocellulose fibers. J Therm Anal Calorim. 2008;91:405-8.

26. Das S, Saha AK, Choudhury PK, Basak RK, Mitra BC, Todd T, Lang S, Rowell RM. Effect of steam pretreatment of jute fiber on dimensional stability of jute composite. J Appl Polym Sci. 2000;76:1652-61.

27. Biagiotti J, Puglia D, Kenny JM. A review on natural fibre-based composites-part I: structure, processing and properties of vegetable fibres. J Nat Fibers. 2004;1:37-68.

28. Demirbas A, Arin G. An overview of biomass pyrolysis. Energy Sour. 2002;24:471-82.

29. Yao F, Wu QL, Lei Y, Guo WH, Xu YJ. Thermal decomposition kinetics of natural fibers: activation energy with dynamic thermogravimetric analysis. Polym Degrad Stab. 2008;93:90-8.

30. Gao M, Li SY, Sun CY. Thermal degradation of wood in air and nitrogen treated with basic nitrogen compounds and phosphoric acid. Combust Sci Technol. 2004;176:2057-70.

31. Chapple S, Anandjiwala R. Flammability of natural fiber-reinforced composites and strategies for fire retardancy: a review. J Thermoplast Compos Mater. 2010;23:871-93.

32. Hill CAS. Wood modification: chemical thermal and other processes. Chichester: Wiley; 2006.

33. Bourgois J, Bartholin MC, Guyonnet R. Thermal treatment of wood: analysis of the obtained product. Wood Sci Technol. 1989;23:303-10.

34. Qu H, Wu W, Wu H, Xie J, Xu J. Study on the effects of flame retardants on the thermal decomposition of wood by TG-MS. J Therm Anal Calorim. 2011;103:935-42. 